ORIGINAL ARTICLE

\title{
Prevalence of Chronic Kidney Disease among Patients Attending an HIV Outpatient Clinic in Kingston, Jamaica
}

\author{
C Price ${ }^{1}$, AK Soyibo ${ }^{2}$, G Barrow $^{3}$, T Clarke ${ }^{4}$, EN Barton ${ }^{5}$
}

\begin{abstract}
The medical records of 983 patients diagnosed with the human immunodeficiency virus (HIV) were reviewed, 501 of whom were female and 482 were male. The mean age was 42.1 years, the mean number of years since diagnosis of HIV was 7.4, and the average duration of highly active antiretroviral therapy (HAART) was 51.7 months. The mean CD4 count at diagnosis was 268.5 cells/ $\mu \mathrm{L}$, but the most recent CD4 count was $461 \mathrm{cells} / \mu \mathrm{L}$, and $85.8 \%$ of the patients were on HAART. The mean CD4 count was lower in those with a glomerular filtration rate (GFR) of $<60 \mathrm{ml} / \mathrm{minute} / 1.73 \mathrm{~m}^{2}$ compared to those patients with only proteinuria and a GFR of $>60 \mathrm{ml} /$ minute $/ 1.73 \mathrm{~m}^{2}$. In the sample population, $76.9 \%$ of the patients had chronic kidney disease stage 3, 7.7\% were in stage 4 and $15.4 \%$ in stage 5 . There were $3.1 \%$ of patients with persistent proteinuria. Hypertension and diabetes mellitus were co-morbidities.
\end{abstract}

Keywords: Chronic kidney disease, HIV, prevalence, proteinuria

\section{Prevalencia de la enfermedad renal crónica entre los pacientes que asisten a una clínica ambulatoria de VIH en Kingston, Jamaica}

\author{
C Price ${ }^{1}, \mathrm{AK}$ Soyibo $^{2}, \mathrm{G} \mathrm{Barrow}^{3}, \mathrm{~T} \mathrm{Clarke}^{4}, \mathrm{EN}_{\text {Barton }}^{5}$
}

\begin{abstract}
RESUMEN
Se revisaron las historias clínicas de 983 pacientes diagnosticados con el virus de la inmunodeficiencia humana (VIH), 501 de los cuales eran mujeres, y 482 hombres. La edad promedio fue de 42.1 años, el número promedio de años a partir del diagnóstico de VIH fue 7.4, y la duración promedio de la terapia antirretroviral altamente activa (TARAA) fue de 51.7 meses. El conteo de CD4 promedio en el momento del diagnóstico fue de 268.5 células/ $\mu l$, pero el más reciente conteo de CD4 fue de 461 células/ $\mu l$, y el $85.8 \%$ de los pacientes se encontraban bajo terapia TARAA. El conteo de CD4 promedio fue menor en aquellos pacientes con una tasa de filtrado glomerular (TFG) de $<60 \mathrm{ml} /$ minuto $/ 1.73 \mathrm{~m}^{2}$, en comparación con los pacientes que
\end{abstract}

From: ${ }^{1}$ General Internist, Turks and Caicos Islands Hospital, Turks and Caicos Islands, West Indies, ${ }^{2}$ Division of Nephrology and Hypertension, Department of Medicine, University Hospital of the West Indies and The University of the West Indies, Mona, Kingston, and Caribbean Institute of Nephrology, Jamaica, West Indies, ${ }^{3}$ Centre for HIV/AIDS Research, Education and Services, University Hospital of the West Indies, Department of Medicine, The University of the West Indies, Mona, Kingston, Jamaica, West Indies, ${ }^{4}$ Department of Medicine, University Hospital of the West Indies and The University of the West Indies, Mona, Kingston, Jamaica, West
Indies and ${ }^{5}$ Division of Nephrology and Hypertension, Department of Medicine, University Hospital of the West Indies and The University of the West Indies, Mona, Kingston; Caribbean Institute of Nephrology; and Centre for HIV/AIDS Research, Education and Services, University Hospital of the West Indies, Kingston, Jamaica, West Indies.

Correspondence: Dr AK Soyibo, Department of Medicine, The University of the West Indies, Mona, Kingston 7, Jamaica, West Indies. Email: demoskey@hotmail.com 
tenian sólo proteinuria y una TFG de $>60 \mathrm{ml} /$ minute $/ 1.73 \mathrm{~m}^{2}$. En la población de la muestra, el $76.9 \%$ de los pacientes tenía enfermedad renal crónica en etapa 3 , el $7.7 \%$ estaba en la etapa 4 , y el $15.4 \%$ en la etapa 5 . Había $3.1 \%$ de pacientes con proteinuria persistente. La hipertensión y la diabetes mellitus fueron comorbilidades.

Palabras clave: Enfermedad renal crónica, VIH, prevalencia, proteinuria

\section{West Indian Med J 2018; 67 (2): 161}

\section{INTRODUCTION}

The human immunodeficiency virus (HIV)/acquired immunodeficiency syndrome (AIDS) was the fourth leading cause of death worldwide, and the impact of this was especially devastating in the developing world where $95 \%$ of the cases were reported to be found (1). From 1982 to the end of December 2005, 10553 AIDS cases were reported in Jamaica, and it was estimated that $1.5 \%$ of the adult population were living with HIV/AIDS (1). In Jamaica, in 2004, AIDS was the second leading cause of death among the 15- to 24-year-old age group and was a leading cause of death in children. It was reported that approximately 25000 people were living with HIV/AIDS in Jamaica (1). HIV-infected individuals with worsening renal function have an increased risk of progression to AIDS and death (2).

Kidney failure, both acute and chronic, occurs in patients with HIV. Untreated acute renal failure can lead to chronic renal failure. Chronic kidney disease (CKD) is a worldwide public health concern; it is under-diagnosed and under-treated in the HIV population. Evidence has indicated that the adverse outcomes of CKD (such as end-stage renal disease [ESRD], cardiovascular disease, chronic malnutrition, various infectious complications, chronic anaemia and premature death) can be prevented or delayed with early detection and treatment (3).

Many definitions of CKD exist; we use the K/DOQI (the dialysis outcome quality initiative, a subset of the National Kidney Foundation [NKF], an American nongovernmental organization focussed on the guidelines governing the management of patients with kidney disease) definition. It defines CKD as kidney damage for three or more months, as defined by structural or functional abnormalities of the kidney, with or without a decreased glomerular filtration rate (GFR; the aggregate filtrate across the basement membrane taking into account all glomeruli in both kidneys expressed as $\mathrm{ml}$ per minute), manifested by pathologic abnormalities or markers of kidney damage, including abnormalities in the composition of blood or urine or abnormalities in imaging tests or a GFR of $<60 \mathrm{ml}$ per minute per $1.73 \mathrm{~m}^{2}$ for three months or more with or without kidney damage (3). End-stage renal disease is defined as a GFR below $15 \mathrm{ml}$ per minute per $1.73 \mathrm{~m}^{2}$, usually accompanied by signs and symptoms of uraemia, or as the need for initiation of kidney replacement therapy. The GFR is considered the best measure of overall kidney function. Normal GFRs vary according to the patient's age, gender and body size. In young adults, the normal GFR is approximately $120-130 \mathrm{ml}$ per minute per $1.73 \mathrm{~m}^{2}$ and declines with age (3). A GFR below $60 \mathrm{ml}$ per minute per $1.73 \mathrm{~m}^{2}$ represents loss of one half or more of the adult level of kidney function (3).

The prevalence of CKD and the predictors of CKD in the HIV-infected population in Jamaica have not been well defined. Mathematical models predict a beneficial impact of highly active antiretroviral therapy (HAART) on the rate of progression to ESRD in HIV patients with AIDS. However, due to the beneficial impact of HAART on the survival of patients with $\mathrm{HIV}$, the prevalence of CKD and therefore the overall number of patients with HIV and ESRD is expected to increase (4). The impact of the HIV epidemic has been projected to have potentially disastrous consequences in the developing world (5). However, funding has been forthcoming in an attempt to increase the supply of HAART at reduced prices or even without costs to the developing nations. However, are we headed for another epidemic, an epidemic of chronic renal disease in an increasing pool of HAART-treated patients? The public health implications to economies already hard pressed to deal with treating HIV-positive individuals according to Western guidelines and protocols would be formidable.

\section{Study objectives}

The objectives of this study were to determine:

- the prevalence of CKD in a sample of $600 \mathrm{HIV-}$ positive patients attending the Centre for HIV/AIDS 
Research, Education and Services (CHARES), a specialist outpatient clinic in Kingston, Jamaica;

- the predictors of CKD in this population and the markers of its severity;

- the duration of HIV infection, use of HAART, duration of HAART use, CD4 count and the use of intravenous controlled substances; and

- the presence of comorbid conditions (diabetes, hypertension, chronic tobacco use) in the patient population.

A HIV-positive individual is one with a positive enzyme immunoassay and a positive Western blot test for HIV. A person with AIDS is defined as a HIV-positive individual with a CD4 count of less than $200 / \mathrm{mm}^{3}$ and/ or an AIDS defining condition. Based on the classification of the Centers for Disease Control and Prevention, United States of America, it will include categories A3, $\mathrm{B} 3$ and $\mathrm{C} 1$ to $\mathrm{C} 3$.

\section{SUBJECTS AND METHODS}

The study was conducted at CHARES at the University Hospital of the West Indies, Kingston, Jamaica. The clinic had more than 1600 patients enrolled at the time of this study. Clinics are conducted four times per week. Approximately 60 patients are seen per week.

This is a cross-sectional retrospective study of a predominantly Afro-Caribbean population of HIV-positive individuals. The medical records of all the patients attending CHARES were carefully reviewed, and their renal failure was noted based on the presence of CKD observed in them.

The GFR was calculated from their serum creatinine values using the Modification of Diet in Renal Disease (MDRD) and Chronic Kidney Disease Epidemiology Collaboration (CKD-EPI) formulae which use many variables for the computation. The initial MDRD formula as defined in the MDRD study consisted of six variables: age, gender, ethnicity, creatinine, urea and albumin. However, the four-variable MDRD equation (involving only age, gender, ethnicity and creatinine) was used because it had been shown to be equally accurate $(3,6,7)$.

An extensive evaluation of the MDRD study equation showed good performance in populations with lower levels of GFR but variable performance in those with higher levels of GFR, and CKD-EPI had good performance in this range (6) with CKD categorization based on estimated GFR and presence of albuminuria as a marker of renal disease.
The data extracted from the patients' medical records were: (a) age, (b) gender, (c) date of HIV diagnosis, (d) ethnicity, (e) weight and height, (f) various serum biomarkers and creatinine measurements over the previous 12 months, (g) previous and most recent CD4 count, (h) the use of HAART and the agents used including the duration of HAART, (i) the presence of chronic illnesses, diabetes mellitus and hypertension, and (j) tobacco and use of intravenous illicit drugs.

A multivariate logistic regression analysis was done to assess the relationship among HIV status, HAART use, CD4 count, hypertension, diabetes mellitus and the presence of more advanced CKD stage.

The identity of all the subjects was protected. The names of the participants did not appear in any published data. Rather than names or registration numbers, codes were used to identify the subjects. The data collection sheet would not be a part of the patient's medical records. All the information gleaned was kept in a safe location, and access to the database was restricted to the investigators.

\section{Benefits of the study}

We believe that this study will be of benefit in the following ways:

- the prevalence of CKD in the HIV population attending this specialized clinic would be assessed;

- the predictors of CKD in the study sample and their correlation to severity would be identified;

- the findings of this study suggested the need to implement strategies for reducing the prevalence of CKD and for the early detection of CKD in the HIV population so that the adverse outcomes of CKD (such as ESRD, cardiovascular disease, chronic malnutrition, chronic anaemia and premature death) could be prevented or delayed with their early detection and treatment; and

- the findings of this study would assist in assessing the future economic impact of the HIV/AIDS epidemic based on the current prevalence of CKD in the HIV population.

\section{RESULTS}

The medical records of 983 HIV patients (501 female and 482 male) were reviewed. Their mean age was 42.1 years. The mean number of years since diagnosis of HIV was 7.4, and the average duration of HAART therapy was 51.7 months. The mean CD4 count at diagnosis was 268.5 cells $/ \mu \mathrm{L}$, and 461 cells $/ \mu \mathrm{L}$ was the most current result. Of this cohort, $85.8 \%$ were on some type of 
HAART: 638 of the patients $(64.9 \%)$ were on first-line HAART and $206(20.9 \%)$ on second-line treatment. A total of $28.3 \%$ of the patients had documented opportunistic infections.

Using MDRD and CKD-EPI, the prevalence of CKD was $2.6 \%$. While $76.9 \%$ of the patients were classified to be at stage 3 of CKD according to the NFK classification, $7.7 \%$ were at stage 4 and $15.4 \%$ at stage 5 of CKD, respectively. Thirty of the patients $(3.1 \%)$ had persistent proteinuria on urine analysis, while 20 of the patients $(2 \%)$ had quantification of proteinuria. Thirteen of the patients had proteinuria of $<1 \mathrm{~g} /$ day, and the rest had proteinuria of $>1 \mathrm{~g} /$ day. In the GFR group, the mean age was 52.5 years, compared to 45.3 years in the persistent proteinuria group. The mean number of years since diagnosis of HIV was 5.9 years in the proteinuria group and six years in the GFR group. Male patients comprised $65.4 \%$ of the GFR group, compared to $62.1 \%$ in the patients who demonstrated persistent proteinuria.

Both the mean initial CD4 count and the most current CD4 count were lower in the GFR group ( 170.8 cells $/ \mu \mathrm{L}$ and 427.8 cells $/ \mu \mathrm{L}$, respectively) than in the proteinuria group (194 cells $/ \mu \mathrm{L}$ and 446 cells $/ \mu \mathrm{L}$, respectively). In all the patients in both groups, HAART was initiated. While the mean duration was 53.5 months in the GFR group, it was 55.4 months in the proteinuria group. The use of second-line therapy was higher in the GFR group $(65.4 \%)$ than in the proteinuria group (38\%). In the GFR group, three of the patients $(11.5 \%)$ had Type II diabetes, four of the patients $(15.4 \%)$ had hypertension, and three of the patients $(11.5 \%)$ had both hypertension and dyslipidaemia. In the proteinuria group, $13.8 \%$ of the patients had hypertension and diabetes. A total of 38.5\% of the patients had a history of opportunistic infection in the GFR group, compared to $48.3 \%$ of the patients in the proteinuria group. Neither group had any tobacco use.

\section{DISCUSSION}

This study sought to determine the prevalence of CKD among patients in a HIV outpatient referral centre. Chronic kidney disease is defined as kidney damage for three or more months, as defined by structural or functional abnormalities of the kidney, with or without a decreased GFR, manifested by pathologic abnormalities or markers of kidney damage, including abnormalities in the composition of blood or urine or abnormalities in imaging tests or a GFR of $<60 \mathrm{ml}$ per minute per $1.73 \mathrm{~m}^{2}$ for three months or more with or without kidney damage. Both the MDRD and the CKD-EPI were used to calculate the GFR.
Hypertension and diabetes are well-documented risk factors for CKD. In this study, three of the patients had only Type II diabetes, four had only hypertension, and three had both hypertension and dyslipidaemia. Cigarette-smoking, hepatitis $\mathrm{C}$ co-infections and intravenous drugs were cited as the risk factors for CKD in other studies. While drug use is not uncommon in Jamaica, it was interesting to note that none of the patients with CKD, either by GFR or persistent proteinuria, used tobacco.

The prevalence of CKD in this study was $2.6 \%$ when using a GFR of $<60 \mathrm{ml}$ per minute per $1.73 \mathrm{~m}^{2}$ and $3.1 \%$ when using persistent proteinuria. There had been wide variabilities in the prevalence of CKD in the HIV population, even within the same geographic location. In a prospective cohort of 22156 HIV-positive military veterans followed up over an eight-year period, $0.1 \%$ of the patients had proteinuria greater than $300 \mathrm{mg} /$ day at the baseline, and $0.2 \%$ had an estimated GFR of less than 60 $\mathrm{ml}$ per minute per $1.73 \mathrm{~m}^{2}$ at the baseline. These vary, compared to other reports which estimated a prevalence of 5-7\% in a study by Estrella et al (8) and a prevalence of as high as $32 \%$ in a study by Szczeech et al (9). Studies from Sub-Saharan Africa had estimates of $2 \%$ in Burundi (10) in contrast to $38 \%$ in Nigeria (11). Interestingly, this was thought to be due to a genetic predisposition likely attributed to polymorphism in the apolipoprotein L1, which is located on chromosome 22.

A low CD4 count at diagnosis of HIV, a high HIV viral load, hepatitis $\mathrm{C}$ co-infection and co-morbidities, hypertension and diabetes are risk factors for developing CKD. In the presence of certain co-morbidities, the exact aetiology of CKD may pose a diagnostic dilemma. Laboratory parameters, such as the CD4 count, viral load, hepatitis serology, HbA1c along with radiological investigations (eg ultrasound), prove invaluable in these cases. Perhaps, more importantly, such cases highlight the need for renal biopsies which would be critical for optimal medical management as the histological patterns may vary as was reported in a study on patients in Sub-Saharan Africa (12).

The Kidney Disease: Improving Global Outcomes recommended screening for renal disease with routine chemistry in patients newly diagnosed with HIV, prior to initiating antiretroviral therapy (ART), prior to any ART regime changes and every three to six months thereafter (13). Urine analysis is also recommended at diagnosis and every three to six months. However, more frequent monitoring is required in patients with co-morbidities such as diabetes and hypertension. Given the economic 
burden associated with CKD and especially the need for dialysis, strict adherence to such protocols is needed to facilitate the early detection of renal disease and timely intervention in its treatment.

Screening and early detection of renal disease with appropriate interventions will result in better outcomes. In patients with CKD, interventions (such as aggressive blood pressure management, glycaemic control along with the use of angiotensin-converting enzyme inhibitors and angiotensin receptor blockers, and appropriate and early initiation of ART) will minimize its progression to ESRD. The importance of these interventions cannot be overstated, especially in resource-limited settings such as Jamaica.

Over the past two decades, there has been a significant improvement in the life expectancy for those living with HIV; the reasons for this are multi-faceted. Public education campaigns have perhaps provided the backbone for the movement to early detection, safer sexual practices, the decrease in discrimination and sensitizing the public to the availability of care for patients living with HIV. In this post-HAART era, it is likely that the patterns of renal disease may mirror those seen in the general population, namely due to hypertension and diabetes.

\section{CONCLUSION}

This study was conducted to determine the prevalence of CKD among patients attending a HIV referral centre in Jamaica. It must be noted that the size of this study sample was small, and more studies with larger samples should be attempted on the screening for renal disease across all HIV treatment centres across Jamaica. These will provide more meaningful data. Other areas for improvement include: sensitizing physicians to screen for renal disease in this at-risk population, along with advocating for aggressive blood pressure and strict glycaemic control in patients with co-morbidities.

\section{REFERENCES}

1. Ministry of Health, Jamaica. Guidelines to the clinical approach to a patient with HIV/AIDS. Ministry of Health, Jamaica; January 2006: $1-2$.

2. Abbot KC, Hypolite I. Human immunodeficiency virus/AIDS associated nephropathy and end stage renal disease in the United States. Nephro 2001; 14: 377-83.

3. National Kidney Foundation, United States of America. K/DOQI clinical practice guidelines for chronic kidney disease: evaluation, classification, and stratification. Am J Kidney Dis 2002 ; 39 (2 Suppl 1): S1-266.

4. Schwartz EJ, Szczech LA, Ross MJ, Klotman ME, Winston JA, Klotman PE. Highly active antiretroviral therapy and the epidemic of HIV + endstage renal disease. J Am Soc Nephrol 2005; 16: 2412-20.

5. Piot $\mathrm{P}$, Bartos $\mathrm{M}$, Ghys $\mathrm{PD}$, Walker $\mathrm{N}$, Schwartlände $\mathrm{B}$. The global impact of HIV/AIDS. Nature 2001; 410: 968-73.

6. American College of Physicians. Annals of internal medicine 2006; volume 145, issue 4.

7. Levey AS, Greene T, Kusek J, Beck G. A simplified equation to predict glomerular filtration rate from serum creatinine [abstract]. J Am Soc Nephrol 2000; 11: 155A.

8. Estrella MM, Parekh RS, Astor BC, Bolan R, Evans RW, Palella FJ Jr et al. Chronic kidney disease and estimates of kidney function in HIV infection: a cross-sectional study in the multicenter AIDS cohort study. J Acquir Immune Defic Syndr 2011; 57: 380-6.

9. Szczech LA, Gange SJ, van der Horst C, Bartlett JA, Young M, Cohen $\mathrm{MH}$ et al. Predictors of proteinuria and renal failure among women with HIV infection. Kidney Int 2002; 61: 195-202.

10. Cailhol J, Nkurunziza B, Izzedine H, Nindagiye E, Munyana L, Baramperanye E et al. Prevalence of chronic kidney disease among people living with HIV/AIDS in Burundi: a cross-sectional study. BMC Nephrol 2011; 12: 40

11. Emem CP, Arogundade F, Sanusi A, Adelusola K, Wokoma F, Akinsola A. Renal disease in HIV-seropositive patients in Nigeria: an assessment of prevalence, clinical features and risk factors. Nephrol Dial Transplant 2008; 23: 741-6.

12. Fabian J, Naicker S. HIV and kidney disease in sub-Saharan Africa. Nat Rev Nephrol 2009; 5: 591-8.

13. Swanepoel CR, Atta MG, D'Agati VD, Estrella MM, Fogo AB, Naicker $\mathrm{S}$ et al. Kidney disease in the setting of HIV infection: conclusions from a Kidney Disease: Improving Global Outcomes (KDIGO) Controversies Conference. Kidney International 2018; 93: 545-59. 